\title{
Taking Stock at the Mid-way Point ${ }^{4}$
}

In March 2010, the Human Rights Unit organised a Commonwealth Mid-Term Review of the UPR. With the UPR process reaching the midway point of its first cycle (20082011 ), the meeting provided an opportunity for states, NHRIs and NGOs to discuss and share their experiences, good practices and lessons learned from their engagement with all stages of the UPR mechanism: (1) consultation and report writing stages; (2) preparation for the review in Geneva; and (3) implementation and follow-up. For each of the above stages three different presentations were made from the perspectives of a state, an NHRI and an NGO. Following each session on a different stage of UPR, participants sat together in their peer groups to discuss each stage in more depth.

The Mid-Term Review sought to promote and strengthen the voices of states and stakeholders (namely NHRIs and NGOs) in the review of the HRC taking place in 2010 and 2011.

This section puts forward all the presentations that were made at the Commonwealth UPR Mid-Term Review. Each contribution is then followed by a brief summary of the points raised in the state, NHRI and NGO discussion groups.

Annex 5 contains a list of the participants who attended the seminar.

\section{Consultations and Drafting a Report}

\section{A view from a state}

\section{Ms Evelyn Keelson, Attorney-General's Department, Ministry of Justice, Ghana}

In fulfilment of UPR requirements, the Attorney-General's Department in the Ministry of Justice was responsible for co-ordinating the drafting of the national report and holding national consultations. A committee was formed within the Ministry of Justice, which included representatives from the Ministry of Foreign Affairs as well. However, due to a delayed start in the preparatory phase, the consultations held were limited in number. Furthermore, a number of factors, such as insufficient awareness of the UPR process, inadequate time to gather information for the report, lack of public engagement with the process, issues with record-keeping and time constraints in training of local officials on the subject, affected the quality of the national report.

\footnotetext{
${ }^{4}$ Please note all contributions are taken from the presentations that were made by individual speakers at the Commonwealth Mid-Term Review in 2010. All contributions represent the personal views of each speaker, and do not necessarily represent those of the Commonwealth Secretariat.
} 


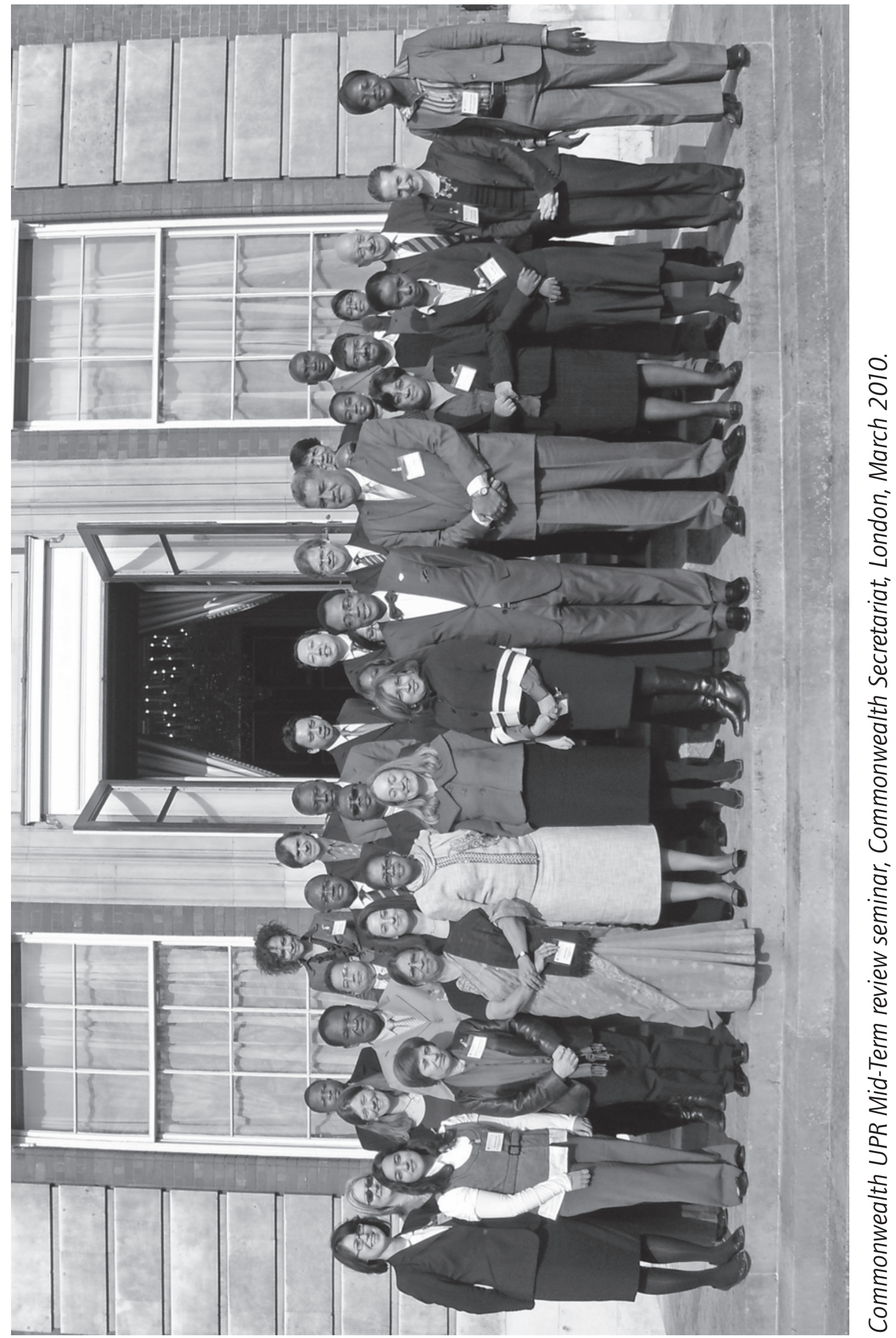


The lack of awareness of the UPR process and time constraints also limited key stakeholders' participation in the process. Further, as the majority of key stakeholders were not aware of Ghana's review, their contribution and involvement was negligible and ultimately affected the quality of the submissions made. The lack of awareness of Ghana's review was even prevalent within the Attorney-General's Office.

Since the preparatory stage of the UPR is a national exercise, it required participation from a high proportion of the population. Ghana did not benefit from the broadest participation because the preparatory phase was low profile and the ordinary Ghanaian citizen was not aware of the UPR process and did not participate in the national consultation. The public at large was not engaged or aware of the content of Ghana's submission. Public ownership of the report was not achieved, and due to the lack of public knowledge most Ghanaians may not monitor or hold duty bearers to account if the recommendations suggested in Geneva are not adhered to.

That aside, inadequate record-keeping by relevant departments and ministries was another factor which adversely affected the quality of Chana's report. This challenge, compounded by time constraints, made it difficult for timely soliciting of relevant information which had a bearing on the report. In addition, Ghana's backlog on obligatory reports to the treaty body mechanism also meant that information for the UPR report needed to be gathered in a most comprehensive manner.

Lack of time also impacted on the effectiveness of capacity-building training for local officials. The training was provided too close to the reporting deadline, leaving little time for those who participated to utilise the knowledge they had gained in producing the report.

Ghana did its best to be forthcoming and transparent in the issues highlighted in the submission. However, there were difficulties in agreeing what the report should contain. Given the diverse composition of working groups, individual members may have had their own preferred way of communicating sensitive issues that are of a national concern. Although unintended, misleading information or misrepresented issues may have occurred, so that there was a risk of not capturing the real human rights situation on the ground.

\section{State discussion group}

- Lack of time was identified as one of the biggest constraints, and the need to begin consultation and report drafting early was highlighted. As the UPR was an unfamiliar process, it was difficult to estimate the scope of the preparations required. 
- Establishing 'systems' or committees to assist in the organisation and planning of the UPR was suggested. These systems could also be used to assist states in duties related to other UN human rights conventions.

- Establishing a system for consultation and preparation of the report was not planned in some cases, and therefore presented strategic difficulties.

- The importance of good stakeholder management was highlighted. The ability to hold timely discussions with stakeholders was noted as a way to alleviate some of the time constraints, making good working relationships important.

- Staff changes and the resulting lost knowledge, expertise and experience of the UPR was noted as another challenging issue. Establishing resource material with adequate funding would be useful to build upon and retain the knowledge gained from the UPR.

- It was noted that sourcing information and ensuring the participation of all government departments in the process was easier if there was a clear, initial political mandate supporting the process.

- Difficulties in obtaining data from across the state's public sector could be reduced with the greater leverage that a clear political mandate would provide.

- Efficiencies could be achieved by developing systems which would be applied across the UN Convention process: aiding the gaining of experience, and retention of knowledge and basic data (names and addresses of NGO contacts).

- The need for continuous stakeholder management and dialogue after the Genevabased review was highlighted as necessary to maintain effective working relationships.

- A number of states proposed a public facing web presence to provide information to (and possibly seek comments from) the public on UPR. Other states noted that the UPR process was a 'reporting back on progress' exercise rather than providing the public's view on the human rights record of the state.

- The importance of remaining flexible was highlighted. What works in one country may not be applicable in another. For example, the relationship with the media or the view of human rights generally will vary from state to state. Depending on these variations, more formalised organisational structures may work in one state but be too heavy in others. Sharing ideas is a way of giving states options from which to consider and adapt to their own context. 


\section{A view from an NHRI}

\section{Zahid Mohammed, former Vice-President, Human Rights Commission of the Maldives}

Maldives is a country in transition to democracy and a culture of human rights. It is within this context that the Human Rights Commission of the Maldives (HRCM) carried out its consultations and report writing for the UPR stakeholder report. On 7 August 2009, Maldives embraced a new constitution with a chapter on rights and freedoms. Maldives is currently in an early stage of liberal democracy, where efforts are being made to establish an institutional framework to promote and protect human rights. In this regard several independent institutions have recently been established, such as the Elections Commission, Anti-Corruption Commission and the Judicial Services Commission.

\section{The process}

In order to prepare for the UPR consultation and report writing process, the HRCM conducted a desk review on good practices adopted by those NHRIs which had already undergone UPR. This review led to a consultative dialogue between the HRCM and local NGOs where a time-frame for the HRCM report was decided. In addition, the most pressing human rights issues were identified, based upon perceived public sentiments and complaints received by the HRCM.

Consequently, the HRCM constituted a UPR team, comprising representatives from all departments and focal points of specific rights. A brief orientation concerning the process was provided for the members of this team, followed by designation of topics to staff.

In addition to conducting document and data reviews, the team compiled lists of stakeholders (focus groups, relevant state authorities and NGOs) prior to holding consultations with the identified groups specific to each topic. The team identified specific atolls and islands for these consultations and conducted trips to places of significance within the country.

Eighteen months before Maldives' review, the HRCM facilitated a meeting of Maldivian human rights NGOs to encourage their participation in the UPR process. During the meeting, the HRCM shared information on the review and subsequently interested NGOs registered to participate in the process. The HRCM stepped out of the NGO response to the UPR once a chair of the NGO UPR group had been appointed.

\section{Advantages}

Early familiarisation with the UPR process, with assistance from the former UN human rights adviser to Maldives, eased the process. The Vice-President of the HRCM participated in a UPR seminar for all Commonwealth states reporting in 2010. This seminar was very helpful to the senior management of the Commission in leading the UPR team. 
The overall consultation and report drafting process served to inculcate and improve the ability of HRCM staff to analyse domestic and international law, since these skills were necessary to compile the stakeholder report. In addition, the involvement and engagement of HRCM staff in this process has contributed to the staff feeling they have ownership of this review.

The HRCM considers its role in facilitating and bringing Maldivian NGOs into the UPR process as an achievement.

The HRCM carried out consultations across many of the islands and atolls. While this widespread information gathering was challenging for the HRCM, it had the advantage of allowing a comprehensive view of human rights in Maldives to be presented in the stakeholder report. This is particularly advantageous because the HRCM believes that both state and NGO reports from Maldives were based on information collection processes restricted to the capital city.

\section{Challenges}

The inadequate availability and lack of data, and cautious co-operation from the relevant state authorities proved challenging. In addition, the government UPR team only spent 45 minutes with the HRCM for the state's own consultation and information gathering purposes.

The HRCM found that the limit placed on the number of pages restricted a complete depiction of issues that were of concern.

A lack of awareness of the UPR process among the public and state agents contributed to challenging circumstances during the information collection process. In the most adverse instance, the HRCM UPR team was denied entry to an island due to public resistance triggered by a misconception allegedly spread by local police regarding the purpose of the HRCM's visit.

The HRCM feels that staff needed more technical training and better orientation on the UPR process to enable them to meet the requirements of this initial stage of the process. These challenges continued beyond the consultation and report writing stage. HRCM activities related to the implementation of the HRCM's recommendations and respective monitoring of relevant state activity could be accomplished more effectively with increased staff exposure and relevant skills.

\section{NHRI discussion group}

\section{Consultations}

- NHRIs, especially those with International Co-ordinating Committee's (ICC) 
A-status, are institutions with a special national role related to human rights. Therefore, there was an expectation that NHRIs would and should fully engage in the UPR process.

- The importance of NHRIs holding consultations in provinces and rural areas was highlighted, helping to ensure a more comprehensive view of the human rights situation across the country. If available, use and involvement of provincial human rights commissions is also important.

- The consideration that consultations and national situation analysis should not be for the UPR alone and should be integrated into NHRIs' standard work was underlined. This would then allow NHRIs to collate and use existing reports and information for the UPR report which would be greatly beneficial.

- NHRIs have a role in encouraging the state to hold consultations at the national level.

- Considering that the NHRI report must be completed and submitted many months before the state report, the importance of NHRIs making contact and consulting with the state at an early stage was noted.

- To ensure that NHRI consultations with the state and civil society are fruitful, the consultations should occur after a first draft of the report has already been circulated.

- Given the importance of public awareness of the UPR process and the often limited NHRI capacity to disseminate information, NHRIs can proactively encourage the state to promote greater awareness of the UPR.

\section{Drafting the stakeholder report}

- Given the strict five-page limit for the stakeholder reports, it was suggested that recommendations made by NHRIs should be about systemic human rights issues. It was noted that NHRIs could ask NGOs dealing with specific issues to elaborate these in detail.

- Recommendations to the state in the NHRI report should be clear, action-oriented and concrete.

- A frank and honest NHRI report is one method of urging the state to follow through in its own report writing.

- Sometimes a state report could appear inaccurate, but this is sometimes an issue of under-reporting, as the state may not have covered all of the key issues. Again, 
it was suggested that a comprehensive NHRI report could help to direct the state to more pertinent concerns.

- Often states do not see the NHRI stakeholder report as separate from the NGO stakeholder reports. This unfortunate perception needs to be re-addressed as it does not give much credence to the distinct status and role that NHRIs hold as separate from NGOs.

\section{A view from an NGO}

\section{Ms Patricia Essel, Programme Manager, Women in Law and Development in Africa (WiLDAF), Ghana}

WiLDAF's engagement in the UPR process was triggered by correspondence from Amnesty International Ghana and International Women's Rights Advocacy Watch that alerted and called for NGOs to engage and participate in the UPR mechanism. In response, WiLDAF reached out to its partners and network members for their inputs on vital human rights concerns and issues that can be incorporated into the stakeholder's report. One prominent issue that surfaced was the lack of women's political participation in decision- making. WiLDAF was able to collect data and information on this to feed into the report.

As a next phase, WiLDAF entered into advocacy with Cabinet ministers and relevant government officials to encourage wider consultations with stakeholders as part of the national preparation for the UPR process. Whilst lobbying the Office of the President, the Attorney-General's office and Ministry of Women and Children's Affairs, WiLDAF expressed commitment and keenness to participate in the process. An NGO consultation workshop was called for, but due to failure in communicating dates of the consultation in time, WiLDAF was unable to participate. Some national NGOs, including Amnesty International, participated in this workshop. Neither the state nor WiLDAF had an opportunity to exchange reports before submission, largely because as the UPR is a new process, there was a lack of familiarity with deadlines and procedures.

WiLDAF's report acknowledged that the Ghanaian 1992 constitution contains fundamental human rights and freedoms and detailed key state mechanisms that serve to promote and protect human rights in Ghana. The report focused on commitments made by the state in promoting women's participation in governance structures and decision making at a global, regional and national level. Statistical information pertaining to women in politics was presented to inform the reality of women's participation. WiLDAF was also able to draw upon previous shadow reports prepared for the Convention on the Elimination of all Forms of Discrimination against Women (CEDAW) and concluding ob- 
servations made to the state. WiLDAF submitted its report electronically to the UPR Secretariat and received an acknowledgement of receipt.

On the day of Chana's review, WiLDAF held a press conference to raise awareness of relevant human rights issues, the significance of the UPR process itself and to listen to experiences of some NGOs in preparing their submissions and their participation in the national consultations.

\section{Challenges and lessons learned}

Lack of information and clarity on guidelines and procedures, and limited knowledge of the new process deprived WiLDAF and other NGOs of full and meaningful participation. Due to time constraints, WiLDAF was unable to hold consultations with its various partner NGOs and network members on producing a consolidated report to the UPR submission. The late start and the five-page restriction for the NGO submission also limited WiLDAF in raising key issues. The need for a national coalition to contribute to such new mechanisms has been realised and work is in progress towards the setting up of such a forum.

\section{Recommendations}

- Exchange information about deadlines and other procedural issues in good time and closely network and correspond with the Commonwealth Human Rights Initiative (CHRI), Amnesty International and other national NGOs;

- Gather information in advance so that documentation and statistical information is readily available;

- Engage with UN mechanisms in all possible ways, including submitting reports to the UPR process, as well as treaty bodies and special procedures;

- Observe government participation at the review;

- Ensure that submission and recommendations are specific to enable targeted follow-up;

- Engage and utilise the media as a medium for creating awareness and enhancing advocacy.

\section{NGO discussion group}

- An area of major concern for the NGOs was the lack of effective, timely and inclusive consultations by states.

- The experiences of many NGOs in the consultation process were not satisfactory. NGOs took it upon themselves to form a coalition, consult widely with partners 
and networks for their stakeholders' report and reach out to the state with genuine willingness to participate in and contribute to the national report.

- The effectiveness of consultations was limited as they were held too late in the process. Lack of knowledge of timelines, procedures and, in some instances, a perceived lack of will from the state to work in a co-operative, transparent and meaningful manner was an area of concern.

- The poor organisation of consultations highlighted the need for strategic planning during the preparatory stages. A well-informed and widely representative advisory or co-ordination committee to not only oversee the preparatory phase, but also to support/steer and follow through the process in an ongoing manner would be useful.

- Limited involvement in influencing and contributing to the national report was a concern. Experience has shown that NGOs working in coalitions to submit stakeholders' reports are important, as well as working in a co-operative manner with the state to contribute to the national report.

- A greater level of transparency, better communication, inclusive and participatory approaches to engage the public at large, and well-co-ordinated and genuine efforts from the state and stakeholders is called for to make Resolution 5/1 real and meaningful.

\section{Preparing for the Review in Geneva}

\section{A view from a state}

\section{Ms Aruna Devi Narain, Assistant Solicitor General, Attorney-General's Office, Mauritius}

Mauritius was reviewed during the fourth session in February 2009 and despite not being responsible for human rights at the time of the review, the Attorney-General's Office was assigned responsibility for preparing and presenting the national report in Geneva.

A national level inter-ministerial committee was set up by the Cabinet and a number of consultations were held with ministries, NGOs and NHRIs prior to finalisation of the national report. The stakeholders sent separate reports through the office of the United Nations Development Programme (UNDP).

Prior to the review in Geneva, delegates from Mauritius participated in a UPR preparatory seminar organised by the Commonwealth Secretariat in London in November 2008. 
The seminar was beneficial as it provided an opportunity to interact with and learn from other Commonwealth states that had been through the UPR process. At this seminar the delegates participated in a mock UPR session and the webcasts of UPR working group sessions of Commonwealth countries were also viewed. Both these exercises proved to be valuable and brought into focus what to expect in Geneva.

For the review in Geneva, the delegation went one day ahead to observe the process and also to observe how other countries participated and responded to questions and recommendations.

\section{Operational difficulties in Geneva}

Mauritius is a small jurisdiction with limited financial resources and this restricted the size of the delegation that travelled to Geneva. Initially, the delegation comprised a fivemember high-level team, including representatives from the Attorney-General's Office, the Prime Minister's Office, the Ministry of Women's Rights and Child Development and the Ministry of Foreign Affairs, but a few days before departure, due to budget restrictions as advised by the Ministry of Finance, the delegation was downsized to a threemember team. This meant that representatives from the Prime Minister's Office and the Ministry of Women's Rights and Child Development were unable to attend the review. This impacted on the level of expertise present in Geneva and put greater pressure on the remaining delegation.

To support the delegation in Geneva, a back-up team was established to be on standby in the capital; given the three-hour time difference between Geneva and Mauritius the team in the capital worked beyond normal office hours to produce a successful review.

The delegation was well prepared to take questions, but given the variety of themes raised it was challenging to collate the responses within minutes to hand them over to the Attorney-General for his response. A considerable amount of time was spent searching through files for the relevant information needed to support responses, thus making the process very pressured. The questions submitted in advance served as useful pointers as to what to expect and the delegation had done its homework as the Attorney-General responded to the advance questions in his initial remarks.

Interacting with the Troika and the OHCHR was a good exercise and strong reliance was placed on the Mauritius mission in Geneva during this diplomatic aspect of the review process. Several sessions were held with the Troika and the draft report with accepted and rejected recommendations was sent to Capital for approval. The level of diplomacy had not been fully anticipated and it was therefore helpful to have the input of those who had been preparing in Geneva and interacting with other delegations for 
many months. It was evidenced that there was absolute duplication of questions and recommendations which could be streamlined if the information raised was organised or grouped under specific thematic areas so that prioritisation became apparent. An experienced person from the Ministry of Foreign Affairs would have been required in the absence of a strong mission in Geneva.

The interplay between human rights and diplomacy illustrates some weaknesses of the UPR system, especially with regards to balancing human rights values with the sovereignty of states and unavoidable foreign policy considerations. Although the Mauritius delegation was not involved in planting questions, encouraging comments were received from countries belonging to the same region and friendly states did consult the Mauritius delegation on questions they intended to ask.

\section{State discussion group}

- The procedure and management of the speakers list was identified as a problem, with 'friendly' states manipulating the system to ensure their dominance during the state interventions. A secure system of booking a speaking slot would be an improvement or the speaking time could be reduced to one minute to allow more states to participate.

- Reducing the time given to the state under review could be one way of creating more time for interventions, but this may negatively affect the response of the state under review to the issues raised.

- To avoid duplication, states making recommendations and interventions should ensure they are not speaking to issues which have already been raised

- Many questions and recommendations were clustered, making it difficult for the state under review to give a clear response.

- The clarity of the recommendations needs to be improved to ensure states are receiving clear, action-orientated advice.

- States should create opportunities for those NGOs in the process of obtaining ECOSOC accreditation to be involved. This could be done by establishing partnerships with ECOSOC-accredited NGOs.

- When discussing what could be done differently during the next cycle, the length of time taken to present the national report was mentioned, with better time management during the next cycle being a key area for improvement.

- A new way of approaching the second cycle was highlighted as an area which 
needed consideration. Devising a new way of approaching the review will be necessary, as it will be based on the recommendations received during the first cycle.

- The need to start discussions on the modalities for the next cycle of review was a high priority, as was looking to include the voice of NGOs to a greater extent.

- To overcome the limitations of a small delegation, the review could be held through video-conference. This would ensure fully informed participation and reduce the financial burden on small states.

- The Commonwealth Secretariat could render assistance to countries that do not have a mission in Geneva.

\section{A view from an $\mathrm{NHRI}$}

\section{Mr David Langtry, Deputy Chief Commissioner of the Canadian Human Rights Com- mission (CHRC), Canada}

The Commission's main contribution to Canada's UPR review was the submission to the Human Rights Council on the implementation of Canada's human rights obligations and commitments.

In Canada, civil society plays a vigorous role in protecting and promoting human rights. As a result, the Commission consulted some $60 \mathrm{NGOs,} \mathrm{with} \mathrm{the} \mathrm{assistance} \mathrm{of} \mathrm{Rights}$ and Democracy, while we developed our submission.

Canada is a federal state, comprising ten provinces and three territories. All of these jurisdictions have their own human rights commissions or tribunals or both. Through the Canadian Association of Statutory Human Rights Agencies (CASHRA), an association of these human rights commissions, we involved these commissions in the preparation of our submission.

\section{During the review}

The Commission attended the plenary session of the UPR Working Group, where the outcome document of the review was tabled. Canada also provided further responses to the recommendations it had received.

It is critical for NHRIs to voice the issues contained within their submissions. However, NHRIs are not given the opportunity to speak at the review so their only option is to conduct advocacy work to influence what is said during the review.

Using the opportunity to give an oral statement after the adoption of Canada's report, the CHRC delivered a statement acknowledging that the UPR process opened channels 
between the state of Canada, human rights organisations and civil society, enhancing transparency and inclusiveness. The Commission prioritised two issues, expressing a wish that the UPR process should help advance the dialogue around the Declaration on the Rights of Indigenous Peoples and hasten Canada's ratification of the Convention on the Rights of Persons with Disabilities.

During the review, there was another option open to the Commission: it could directly lobby the representatives of member states in Geneva. While the Commission had been able to bring its views and concerns to the attention of the international community through its submission to the Council, the CHRC did consider the strategy of lobbying representatives of other states and seeking their support in commenting on Canada's performance in human rights matters.

The CHRC ultimately decided not to pursue this option, but the Commission notes that several Canadian NGOs did so, and were quite successful. They provided those state representatives with briefings, ready-made questions and recommendations. Several of these questions and recommendations were used by some member states during the Interactive Dialogue - sometimes verbatim.

\section{After the review}

While the introduction of the UPR marked a milestone in the work of the Human Rights Council, most would agree that it is just a beginning: the hard work comes afterwards, with the implementation of the commitments made by the state under review.

The Commission hopes to contribute to the implementation of the Council's recommendations that were accepted by Canada, as well as to the monitoring of progress made in that regard.

At the time of writing, the review was concluded less than a year ago, so the mechanisms to follow up on Canada's review remain to be defined, including the role that the Commission and civil society will play in the follow-up.

\section{NHRI discussion group}

- Speaking time available for NHRIs is short, therefore key concerns should be prioritised.

- Funding for NHRIs attendance in Geneva is a key issue, often only one person from a NHRI been able to attend. For this reason, strategic planning of how to use the time in Geneva is key.

- It was suggested that rather than lobbying other states - which could have a 
negative impact on NHRIs' credibility - it would be preferable for the NHRIs to take up issues with the state earlier at the national consultation phase. In other words, to lobby at national parliament level rather than internationally.

- The possibility of NHRI opportunities to lobby states to make voluntary commitments in the lead-up to the UPR was discussed.

- NHRIs could organise an event in their home country to telecast the UPR review as part of a campaign to raise awareness of the UPR and make the process more accessible to those without the resources to participate in Geneva or watch webcasts with their own facilities.

\section{A view from an NGO}

\section{Mr Andrew Khoo, Chair, Human Rights Committee, Malaysian Bar Council, Malaysia}

In the preparation of the report at the national level, some of the Malaysian NGOs were not included in the discussions of the national report, nor had they been privy to much of the content of the report, as it was embargoed until its actual submission to the Human Rights Council. This limited the level of engagement of NGOs in contributing to the national report through highlighting contradictions or asking for clarifications from the state. It would have been beneficial if NGOs had had more opportunities to work with the state and Troika states so that the final adopted report incorporated the NGO's inputs as well. For a meaningful UPR process, the national report needs to reflect the concerns of every individual and citizen of the state under review, and limiting NGO engagement prevents this from happening.

One of the very first challenges that an NGO may come across in its aim to participate in the review in Geneva relates to funding constraints. With many NGOs struggling to finance their everyday activities, funding a trip to Geneva may simply be impossible. Though a fund to provide financial assistance for governments to participate in the review exists, similar funding is currently not made available to NGOs. It is submitted that if the HRC is sincere about involving NGOs, then financial assistance needs to be extended to all stakeholders in the new process.

The newness of the process, in addition to lack of orientation and knowledge of how the UN system operates, also presents a challenge for NGOs who have never travelled to Geneva before. The process as it stands, however, favours those who are aware of how the HRC operates.

Obtaining ECOSOC accreditation is another obstacle for many NGOs engaging with the 
UPR process for the first time. To participate in the UPR process in Geneva, NGOs must have obtained ECOSOC accreditation. Currently, obtaining ECOSOC status takes a minimum of two years, and for those hearing about the UPR for the first time accreditation will not be finalised in time for participation. Furthermore, an NGO that applies for ECOSOC status must be legally or formally registered in their home country. For those organisations whose work is seen to be politically sensitive this may not always be possible. Non-accredited NGOs may have to rely on accredited national or regional NGOs whose ECOSOC accreditation they can utilise. This alternative may not always be feasible and many NGOs may be unable to make oral submissions in Geneva. Furthermore, the time allocation of two minutes for NGOs making oral submissions is totally insufficient to raise any meaningful intervention on relevant issues and concerns.

Lobbying delegations in Geneva was not an easy task, as states making submissions in the review had finalised the contents of their submissions well in advance. While some states were sympathetic to the lobbying, they decided not to raise non-controversial issues in their submissions. This therefore limited the opportunity to influence questions and recommendations submitted by the participating states. Being present in Geneva weeks before the review might have resulted in more successful lobbying, but that said, the financial constraints for NGOs hinder an early arrival in Geneva.

One of the weaknesses of the UPR process relates to states signing up for a speaking list at the review. As witnessed in Malaysia's review, missions of the states began queuing at $5.45 \mathrm{am}$ to register to speak, and some 83 countries were able to register, but to due time constraints only 60 countries were actually able to speak. Of these, 44 were members of either the Association of Southeast Asian Nations (ASEAN), the Organisation of the Islamic Conference or the non-aligned movement. The 'friendly' states had more say in the process and prevented other states from having an opportunity to speak. This procedure, through the help of 'friendly' states, allows the state under review to obtain selective and less challenging recommendations.

To increase the influence that NGOs can exert in Geneva there is need for an increase in logistical and financial support. Funding needs to be readily available and the ECOSOC accreditation requirement needs to be waived to make it possible for many NGOs to even be present during the UPR process. States participating in the review need to be flexible to incorporate any last minute lobbying carried out by the NGOs. To maximise the opportunity for NGOs to effectively participate in the UPR process, the Commonwealth Foundation could consider setting up an office in Geneva and a Commonwealth Trust Fund could be established to assist NGOs. 


\section{NGO discussion group}

- In comparison to NGOs, states and missions present in Geneva were well prepared for the process; there were limited opportunities for NGOs to participate, with some states declining lobbying requests made by NGOs.

- The overcrowding of the speakers list is an issue of concern as it allows 'friendly' states to dominate the process and thus prevent genuine human rights issues from being raised.

- Preparation for the review needs to have an earlier start. A stronger network of NGOs or a coalition of NGOs is required to make the government more accountable.

- Recommendations submitted by NGOs in the stakeholder reports should be more specific and action-orientated, rather than generic statements.

- Many NGOs face financial limitations which prevent them from fully participating in the Geneva-based review. The full and meaningful participation of NGOs will ensure that the real human rights situation of a country is revealed and to this end a voluntary trust fund for NGOs and provisional funding from the state is suggested.

- Lobbying can be very effective if targeted preparations are made in good time. It could also increase the impact of NGO submissions ensuring specific recommendations directed at the Troika and other states participating in the review.

- A communication strategy which utilises the media and other technologies such as translated webcasts (in local languages) could be a good method to educate citizens on the review process and outcomes. Press conferences held on the day of the review were discussed as being a good publicity method.

- As an informal practice, as in the review process, Troika meetings with the state under review could include NGO participation as observers.

- Networking with international NGOs and ensuring a dialogue with various missions in the capital could also increase the voice of national NGOs in the review. ECOSOC procedures should be slightly relaxed for the participation of national NGOs in Geneva. 


\section{UPR Follow-up and Implementation of Recommendations}

\section{A view from a state}

\section{Mr Lopeti Senituli, Adviser to the Prime Minister, Office of the Prime Minister, the Kingdom of Tonga}

The Troika of rapporteurs selected by the HRC to facilitate the review of the Kingdom of Tonga were Nigeria, Qatar and Mexico. A list of questions was prepared in advance by Latvia, the Netherlands and the UK, and transmitted to Tonga through the Troika.

During the Interactive Dialogue of Tonga's review, 34 delegations made interventions praising Tonga for its participation in the UPR process, its high-level representation and the quality of both its presentation and its national report. The Working Group in its report on Tonga identified 42 recommendations. Of these, Tonga expressed its support for 31 and non-support for 11.

Political reform has been Tonga's primary focus since its UPR review. In Tonga's national report it was detailed that the legislative assembly had established a tripartite committee made up of equal representation from the Cabinet, the nobles' representatives and the people's representatives. Their role was to develop a consensus model for a reformed legislative assembly.

However, by the third quarter of 2008 it had become obvious that the tripartite committee would not be able to come to any agreement on a consensus model. The legislative assembly, on the recommendation of the Government, moved forward and established a Constitutional and Electoral Commission (CEC) which has similar but more extensive terms of reference than the original tripartite committee. Membership of the CEC was restricted to non-members of the legislative assembly and Cabinet, despite nominations being made by the Cabinet, the nobles' representatives, the people's representatives and the Judicial Services Commission.

The CEC started its work in January 2009 and presented its final report with recommendations to His Majesty and the legislative assembly in November 2009. By December 2009, the legislative assembly had completed its deliberations and ballot on the 82 recommendations made by the CEC, and agreement was reached on a new consensus model of parliament. The consensus model specified that all members of the legislative assembly are to be elected, the Prime Minister, as the Head of Government, will be selected by the elected members and the Prime Minister may then select his Cabinet from those elected members. The privilege of choosing additional Cabinet members from outside Parliament when deemed necessary remains. 
The Electoral Boundaries Commission is currently completing its report on new electoral constituency boundaries and necessary amendments to the Constitution to enable the new legislation are being drafted. The Government is committed to holding elections for a reformed legislative assembly by November 2010. It is on this reform that the Tongan Government has focused its energies and resources since it appeared before the UPR working group in May 2008.

Due to Tonga's focus on its national political reform there has been little opportunity to deal with any of the other commitments made in Geneva, and specific offers of technical assistance made by New Zealand, Switzerland and Australia have not been actively followed up. Tonga is grateful for these regional offers of support, which will assist them in building the required capacity to meet treaty body reporting obligations and implement the recommendations emanating from the UPR process, and it hopes that these offers still stand.

Despite expressing support in Geneva for those recommendations that suggested Tonga should sign and ratify CEDAW, in September 2009 Tonga's legislative assembly voted not to ratify the convention. This was largely due to Tonga's refusal to support those recommendations which suggested consideration should be given to repealing the alleged discriminatory practice in inheritance laws. Tonga wants to reserve the right not to apply the provisions of Article 2 of CEDAW to the succession to the Tongan throne and nobility and hereditary titles, and to land laws; this was one factor which prevented ratification.

Similarly, Tonga wants to reserve the right not to apply the provisions contained in Articles 12 and 16 on family health and marital customs relating to access to healthcare services, including family planning, choice of spouse, spacing of children, and the ownership and disposition of family property.

If Tonga were to ratify CEDAW, an amendment to Clause 32 of its Constitution which specifies that succession to the throne shall be by the eldest male child and the heirs of his body would have to be made so as to allow the eldest female child to ascend to the throne. Similar amendments would have to be made to Clause 111 of the Constitution and Section 82 of the Land Act to enable female children to inherit hereditary titles and estates, as well as registered tax and town allotments, if they are the oldest children.

Within this context, it should be noted that there is no freehold title in Tonga and that land is inalienable. The highest form of property rights that one can hold in Tonga is a life interest. By entrenching succession to family land holdings through the oldest male child and prohibiting its alienability, Tonga virtually guarantees that the family land remains within the family forever, and that the land remains in Tongan hands in perpetuity. 
Although Tonga's laws governing succession to family land holdings may seem to discriminate against women, in the same vein it can be deemed to be discriminating against the younger male child. However, it should be emphasised that women have the same rights as men to lease land.

There have been suggestions that Tonga could ratify CEDAW with reservations. Unfortunately, the key articles on which Tonga has reservations, Articles 2 and 16, have been held by the Committee on the Elimination of Discrimination Against Women as central to the object and purpose of CEDAW, and therefore any reservations on them are 'impermissible' under Article 28(2) which states very clearly that any '... reservation incompatible with the object and purpose of the present Convention shall not be permitted'.

Tonga is especially keen to learn from Commonwealth member countries with a similar constitutional make-up to Tonga, which have ratified CEDAW with reservations, as to how they have been able to overcome the 'impermissibility' stipulation in CEDAW.

It must also be emphasised that Tonga's decision not to ratify CEDAW should not be misinterpreted as a refusal to recognise, promote and protect women's rights.

In 2007 Tonga amended its Nationality Act to allow Tongan women who marry non-Tongan citizens, and their children, to retain their Tongan nationality. In 2010 the Tonga Government made a policy decision to amend its land laws so as to allow the eldest female child to succeed in situations where there is no male heir, to register the family allotment and to pass it on to her eldest male child when he comes of age.

These examples are testimony that the legislative assembly and the Government support women's rights and are actively engaged in promoting the rights of women, despite not having ratified CEDAW.

\section{State discussion group}

- Some participants expressed their concerns that some recommendations were rather vague and therefore difficult to implement.

- Other recommendations could not be implemented due to changes in policy occurring in governments, in addition to time constraints on the states to implement these recommendations.

- Engagement with civil society at the follow-up and implementation stage would be beneficial to all parties involved. 
- It was suggested that through supporting and strengthening NHRIs, reaching targets of implementation of recommendations could be greatly improved.

- Levels of awareness were raised as a pressing issue - most people are not fully aware of the principles of human rights in general or of the work of the UPR.

- A publication setting out best practices, collaborations, the uses of technology and training is strongly recommended by the states.

- Almost all recommendations dealt with civil and political rights; the states group said that they would like to see more recommendations around social and cultural rights.

- In the actual process of implementing the recommendations made in Geneva, a national monitoring committee was identified as well placed to gather and review information being fed through by all the different ministries working on implementation, in order to facilitate information sharing and avoid cross-overs.

- Challenges to the implementation of recommendations were identified: constitutional challenges, sensitive issue areas (such as the death penalty and sexual orientation) and popular traditional religious beliefs were identified as areas of difficulty in the implementation of recommendations.

- A positive step that the Commonwealth Secretariat could take to follow the implementation stage of the UPR process would be to design a monitoring mechanism of its own, and from this derive a database of best practices.

\section{A view from an $\mathrm{NHRI}$}

\section{Advocate Lawrence Mushwana, Chairperson, South African Human Rights Com- mission (SAHRC), South Africa}

South Africa was one of very few states thus far that chose not to submit a written report prior to appearing before the HRC. Rather, the government chose to only make an oral submission on the day of the review. Further, following the Interactive Dialogue stage in Geneva, South Africa did not give any indication whether any UPR recommendations had been accepted or rejected. In fact, the state chose to give no clear response to any of the recommendations.

The SAHRC is engaging in post-UPR activities in three ways: encouraging the state and civil society to engage with the UPR and the international human rights system; mainstreaming UPR recommendations into the Commission's overall work, and aligning its work and programmes with specific UPR recommendations; and encouraging the state and civil society to engage with the international human rights system. 
The possible achievements of the UPR at the implementation stage will be further strengthened through greater participation of the state and civil society in the process. The Commission believes that for the international human rights system to work effectively to promote and protect human rights on the ground, there is a need for three strong and active participants: the state, the NHRI and civil society. It is thus deemed imperative that the Commission work towards strengthening both the state's and civil society's capacity to engage.

State: South Africa's approach and response during the review in Geneva must be looked at as part of a larger picture of lack of compliance with international human rights mechanisms. South Africa has never submitted an ICCPR report, and the state reports with respect to the Convention on the Rights of the Child (CRC), the Convention Against Torture (CAT), CEDAW and the Convention on the Elimination of Racial Discrimination (CERD) are all overdue. The SAHRC supposes this lack of compliance is due to a lack of communication between state officials in Geneva and the relevant government departments in South Africa. It also must not be forgotten that South Africa is a new entrant to the international human rights system, having been excluded prior to 1994. The state has many priorities to attend to, so the lack of participation at an international level should not necessarily be read as a lack of commitment to human rights obligations.

The SAHRC is aware of these challenges and is intent on engaging with government to improve its activities at an international level. The commissioners will interact at a political level to obtain greater clarity and understanding regarding South Africa's relative lack of engagement.

Civil society: There is ongoing work through which the SAHRC encourages domestic civil society to strengthen its involvement at an international level. Some of the Commission's work relating to recommendations runs alongside and in consultation with civil society.

\section{Mainstreaming UPR recommendations into the overall work of the Commission} Since the review of South Africa, the SAHRC has always worked from the premise that UPR recommendations must be mainstreamed into the general work of the Commission. The UPR is not viewed as a stand-alone project, but very much as a part of the daily work of the Commission. Commissioners and staff are cognisant of the recommendations and seek to promote and advance them.

As part of this mainstreaming, it is the view of the SAHRC that UPR recommendations must be read alongside the recommendations already made by the UN Treaty Bodies to South Africa.

Following the adoption of South Africa's UPR report in Geneva, the UPR recommenda- 
tions have been one of the sources used to guide the Commission in the drafting of its strategic plan.

\section{Aligning Commission work in line with specific recommendations}

The SAHRC decided to connect areas of its work with the recommendations made to the state. All 22 recommendations have been allocated as the responsibility of either a Commission committee, programme or topic co-ordinator. In addition, the Commission's work is either being specifically aligned to each recommendation or the relevant committee or staff must monitor issues related to their allocated recommendation(s). The SAHRC's strategic plan provides that all recommendations and related work will be tracked.

The following examples of SAHRC work and activities all directly correspond to UPR recommendations made to South Africa:

Corporal punishment - The Commission is involved in ongoing work with civil society stakeholders, at both a national and regional level, to move towards the abolition of corporal punishment in the home. In a debate about opportunities for strategic litigation on the issue, it was decided that this human rights concern is better addressed by working towards general consensus on this controversial issue, rather than simply enforcing a legal ban by judicial decision. This decision was made particularly because there are many voices of dissent within certain communities on a total ban on corporal punishment.

The strategy now is establish a children's Committee to strengthen ties with relevant state and civil society actors in addressing how to best promote positive non-violent methods of discipline and to address the ongoing use of corporal punishment in some schools.

Torture - The SAHRC has established an anti-torture committee which seeks to ensure the criminalisation of torture, the ratification of the Optional Protocol to the Convention Against Torture (OPCAT) and the establishment of a National Preventative Mechanism.

Gender - Gender work in South Africa has been largely relegated to the Commission on Gender Equality (CCE). However, it is clear that gender is a human rights issue and the many UPR recommendations relating to gender attest to this. The SAHRC has decided to play a stronger role in this area and a formal consultative strategy between the Commission and the CGE will be adopted to ensure common actions and approaches to gender matters.

Ratifications - Following the UPR review, the SAHRC and civil society ran a campaign calling on the state to ratify the International Convention on Economic, Social and Cultural Rights (ICESCR) and its relevant optional protocol. With regards to other human rights 
treaties that South Africa has yet to ratify, the strategic plan of the SAHRC provides that the Commission will carry out activities to move towards additional ratifications.

Education - South Africa received recommendations that it should continue to promote and facilitate the right to education, particularly amongst economically disadvantaged children, and to continue disseminating a culture of human rights in its education institutions. The Commission will continue existing work in this area, carrying out enquiries and providing input to the government officials responsible for education. The Commission will also engage with a parliamentary analysis of South Africa's education challenges and will set up a committee on education issues.

Racism and xenophobia - The SAHRC is drafting a new National Action Plan against racism and has been working on a report speaking to the rule of law and impunity issues arising out of the May 2008 xenophobic violence in South Africa.

The SAHRC strongly believes that the UPR process provides an important tool to direct and allow the Commission to carry out its constitutional obligations at a domestic level. The achievements of the UPR will be further strengthened through greater participation in the process by government and domestic civil society.

\section{NHRI discussion group}

- It was advised that UPR recommendations should be linked to the NHRI's strategy and to both the ongoing and future work of the NHRI within the scope of its mandate.

- NHRIs should lobby and monitor the state with regard to the implementation of recommendations that come out of the UPR.

- NHRIs could play a role in identifying and correlating state agencies to various UPR recommendations to determine which agencies have the role and responsibility for implementation.

- The pre-review dialogue between the state, domestic NGOs and the NHRI on human rights issues should be viewed as an opportunity to continue conversations and relationships during the implementation stage.

- The fact that a state has accepted a number of UPR recommendations and has shown a political willingness to engage on human rights should be capitalised on by NHRIs.

- It is possible that the UPR has rekindled the interest of state actors and the public in the work of NHRIs - this is another positive opportunity for NHRIs. 
- Where possible, NHRIs could have a strong role in raising awareness of the recommendations that come out of the UPR.

- NHRIs could request international implementing agencies and organisations to provide technical support to NHRIs in applicable areas where states may face challenges in implementing the recommendations.

- NHRIs have an important role to play in the post-review UPR stage with regard to the implementation of recommendations. To strengthen the ability of NHRIs to carry out this important work it is suggested that NHRIs appeal to states to expand the mandate of NHRIs to specifically refer to the UPR.

- A big challenge faced by NHRIs with regard to UPR follow-up is that there is often a lack of state recognition of the specific role of NHRIs. NHRIs should continue to consult and maintain dialogue with the state to ensure more clarity on the side of the state with regard to the role of NHRIs in UPR follow-up. This could also assist NHRIs in their endeavours to receive adequate resources and funding for this stage of the UPR process.

\section{A view from an NGO}

\section{Ms Sultana Kamal, Executive Director, Ain o Salish Kendro (ASK), Bangladesh}

Although the UPR Forum Bangladesh has easy access to the highest levels of authority, unfortunately the Bangladesh Government categorically only accepts information and/or recommendations received through its own channels. It depends on its intelligence agencies and civil servants rather than on citizens' groups or NHRIs. A state of denial persists in government systems, which means that providing information has proved mostly futile and getting information from the Government seems almost impossible.

Historically, the relationship between the state and even between various groups of citizens has inherited some grey areas of mistrust which hinder effective co-operation and information sharing. Unfortunately, this trend has negatively influenced interactions and the government does not take civil society into account. Although friendly interactions occur at a personal level, the relationship can be quite confrontational. For example, criticisms are considered a 'betrayal' and historically, international mechanisms have been used to criticise the Government, creating the perception that NGOs use these mechanisms to embarrass their own government.

Implementation of the UPR recommendations has regional and international implications and therefore is not exclusively a national affair. The sensitivity existing within the system plays an important role in the effort to implement UPR recommendations. The 
relationship with neighbouring countries has a strong bearing on the action a government decides to take in upholding and implementing voluntary pledges and recommendations.

Unfortunately, the UPR process has failed to create the sense of ownership which should exist amongst the public as well as the state authorities. Many recommendations are often rejected by state officials as foreign ideas that do not suit local culture and may offend the religious sentiments of the people. The notion that human rights principles are a Western concept and that they are difficult to implement in 'other' societies needs to be addressed. There must be a wider belief that human rights are inherent and universal if efforts to secure them are to be successful.

Further, political compromises made by the state in the name of national security, protection of religious and cultural traditions, and national identity impact on the enjoyment of human rights by all, especially women, children and disadvantaged groups.

The review of Bangladesh was prepared by the caretaker government led by the military without consultation with any section of society. The new government that came to power towards the end of December 2008 had very limited time to carry out consultations. Under those circumstances, a group of leading NGOs took it upon themselves to form the UPR Forum, which consisted of 17 organisations, with ASK as the secretariat. Its mandate was to work on the reporting process and on the report content. The Government responded to the Forum's call for co-operation and made a commitment to incorporate as many recommendations as possible suggested by the Forum. The Forum has been instrumental in encouraging the government to engage with the UPR recommendations, and the present government is now working on the following issues:

- Trials of war criminals

- Rights of persons with disabilities

- Domestic Violence Prevention Act

- Equal property rights for women

- A code of conduct for the protection of the rights of domestic workers, particularly child domestic workers

Implementation of the Chittagong Hill Track Accord has slowed down, giving way to more conflicts in that area. 


\section{NGO discussion group}

- In the follow-up and implementation stage of the UPR, one NGO prepared a reporting card to aid them in monitoring the progress which was being made by its government. Efforts to ensure a dialogue between the NGO and the state were also made.

- The need for NGOs to engage with government was highlighted as being necessary during the follow-up and implementation stage of the UPR process. A governing steering committee that could develop a work plan that included NGOs, with the aim of implementing recommendations, was suggested, as was the suggestion to establish a coalition of NGOs. Creating and maintaining good working relationships with key government ministers was also mentioned as an effective way for NGOs to ensure their involvement in the implementation stages.

- NGOs should seek to be included in any consultation on National Action Plan or planning and should make efforts to establish periodic consultations with the relevant NHRIs.

- It was also suggested that NGOs could publish reports on the status of implementation. A categorised database of recommendations could also be established. These initiatives should be done with the involvement of the state.

- In the follow-up and implementation stage of the UPR process a lack of engagement and political will was highlighted as a challenge. The need to keep the public informed and ensure transparency of the process was also noted, as was the need for a strong democratic infrastructure to ensure that governments can be held accountable. The lack of public information presented challenges to NGOS, and in one case it was noted that the government did not report back to any NGOs, limiting the process to interaction between states. 